\title{
A MORTE PRECOCE DO PESSEGUEIRO ASSOCIADA À FERTILIDADE DO SOLO ${ }^{1}$
}

\author{
NEWTON ALEX MAYER ${ }^{2}$, BERNARDO UENO², VALÉCIA ADRIANA LUCAS DA SILVA ${ }^{3}$, \\ RICARDO ALEXANDRE VALGAS ${ }^{2}$, CARLOS AUGUSTO POSSER SILVEIRA ${ }^{2}$
}

RESUMO- A morte precoce do pessegueiro é uma síndrome caracterizada por um colapso das plantas ao final do período de dormência, cujas causas envolvem diversos fatores bióticos e abióticos. Objetivou-se avaliar a associação da morte precoce do pessegueiro com à fertilidade do solo. Amostraram-se a rizosfera, para análise química, sob a copa de plantas sintomáticas e assintomáticas, com idade entre dois e oito anos, em nove pomares comerciais localizados nos municípios de Pelotas e Canguçu, no Rio Grande do Sul, totalizando 108 amostras. De acordo com os resultados, a obtenção de uma função discriminante para classificar as plantas em duas categorias, como sintomáticas ou assintomáticas, não proporcionou resultado satisfatório, pois a taxa de classificação errônea superou 40\%. A análise de variância individual mostrou que, univariadamente, não existe diferença significativa na fertilidade do solo entre os dois grupos de plantas amostradas. Embora a fertilidade do solo, na maioria dos pomares amostrados, esteja aquém do recomendado para a cultura do pessegueiro, a ocorrência da morte precoce do pessegueiro não apresentou relação com os atributos químicos de fertilidade do solo. O resultado sugere que outros fatores, como os aspectos físicos do solo e o uso de misturas varietais de cultivares-copa como porta-enxerto, possam estar envolvidos na ocorrência de morte precoce do pessegueiro.

Termos para indexação: pH do solo, nutrientes do solo, síndrome, Prunus spp., Rosaceae.

\section{THE PEACH TREE SHORT LIFE ASSOCIATED WITH SOIL FERTILITY}

\begin{abstract}
The Peach Tree Short Life (PTSL) is a syndrome characterized by a tree collapse at end of dormancy and its causes involve several biotic and abiotic components. The objective of this research was to study if there was association between PTSL and soil fertility. Rhizosphere samples were collected for chemical analysis from two to eight-years-old symptomatic and asymptomatic trees (paired trees), at nine commercial peach orchards located in Pelotas and Canguçu, state of Rio Grande do Sul, Brazil, totaling 108 samples. According to the results, discriminate function for classifying trees into two categories (symptomatic or asymptomatic) did not provide satisfactory results because the misclassification rate exceeded $40 \%$. The analysis of variance showed that there is no significant difference in soil fertility between two groups of trees sampled. Although soil fertility, in most orchards sampled, is below than recommended level for peach, the occurrence of PTSL was not associated with soil chemical properties. The present research suggests that other factors such as soil physical properties and the use of non-selected varietal mixtures of scion cultivars as rootstock, may be involved in PTSL.
\end{abstract}

Index terms: soil pH, soil nutrients, PTSL syndrome, Prunus spp., Rosaceae.

\footnotetext{
${ }^{1}$ Trabalho (156-14). Recebido em: 09-05-2014. Aceito para publicação em: 19-08-2014.

${ }^{2}$ Pesquisador da Embrapa Clima Temperado, BR 392, km 78, Caixa Postal 403, CEP 96010-971, Pelotas-RS. E-mail: alex.mayer@ embrapa.br; bernardo.ueno@embrapa.br; ricardo.valgas@embrapa.br; augusto.posser@embrapa.br

${ }^{3}$ Graduanda em Ciências Biológicas na Unviersidade Católica de Pelotas (UCPel), bolsista PIBIC/CNPq. E-mail: valecia_adriana@, hotmail.com
} 


\section{INTRODUÇÃO}

A síndrome da morte precoce do pessegueiro (MPP) é caracterizada por um colapso e morte da copa das plantas no final do inverno ou início da primavera, acompanhada de injúrias provocadas pelo frio e/ou cancro bacteriano causado por Pseudomonas syringae (RITCHIE; CLAYTON, 1981). Os sintomas são perceptíveis no final do período da dormência, com a ocorrência de necroses e odor azedo debaixo da casca das ramificações, redução ou paralisação do crescimento, evidenciada pela diminuição ou falta de brotação e floração. Observa-se também a morte de brotos, de parte da planta ou mesmo de toda a copa (BRITTAIN; MILLER Jr., 1978; CAMPOS et al., 1998).

No Brasil, constatada desde o final da década de 1970 no Estado do Rio Grande do Sul, os danos têm-se intensificado nos últimos dez anos, especialmente nas regiões persícolas de Pelotas e da Campanha, sendo detectados, em casos mais graves, pomares com até $90 \%$ de plantas sintomáticas (MAYER et al., 2009; MAYER; UENO, 2012). Os estudos realizados no Rio Grande do Sul não evidenciaram correlação da ocorrência da síndrome com a idade das plantas, localização das plantas no pomar, plantas individuais ou grupos de plantas nem mesmo com a cultivar-copa (CARNEIRO et al., 1993; CAMPOS et al., 1998). Entretanto, em visitas técnicas realizadas, tem-se observado que a síndrome tende a ocorrer em solos mais arenosos ou pedregulhosos, de forma agregada, em locais mais afastados de pedras e das matas limítrofes dos pomares.

Diversos fatores são citados na literatura internacional como causas ou fatores que predispõem a ocorrência desta síndrome. Dentre os fatores bióticos, são citadas anomalias anatômicas e redução da produção de vasos nos ramos novos, o parasitismo do nematoide anelado Mesocriconema xenoplax, o cancro bacteriano causado por Pseudomonas syringae pv. syringae e o uso de porta-enxertos suscetíveis. $\mathrm{O}$ baixo $\mathrm{pH}$ do solo, as altas concentrações de alumínio e de sulfato de enxofre no solo, a textura francoarenosa, as injúrias provocadas pelo frio, as flutuações de temperatura no inverno, as restrições físicas do solo, os danos físicos às raízes provocados por grades de disco e arados, a poda realizada precocemente no outono e as práticas culturais inadequadas são fatores abióticos também associados à síndrome (JONES; JONES, 1974; BRITTAIN; MILLER Jr., 1978; WEHUNT et al., 1980; RITCHIE; CLAYTON, 1981; REILLY et al., 1986; NYCZEPIR, 1990; OKIE et al., 1994; WERNER et al., 1995; MARAFON et al., 2009; LUNA-GUERRERO et al., 2011). Folhas e ramos de plantas sadias apresentaram menores teores de $\mathrm{Al}, \mathrm{Fe}$ e $\mathrm{Ca}$, comparativamente às plantas com morte precoce (JONES; JONES, 1974; SHARPE; REILLY, 1986), porém as alterações dos níveis de nutrientes, verificadas nesses estudos, não esclareceram se são a causa ou a consequência desta síndrome (SHARPE et al., 1989).

Sharpe e Reilly (1986) avaliaram a fertilidade do solo em pomares de pessegueiro afetados pela morte precoce na Geórgia e na Carolina do Sul, nos Estados Unidos, amostrando a rizosfera ao redor das plantas sadias e daquelas com sintomas de morte precoce. Os autores constataram poucas e esporádicas diferenças entre as amostras de ambos os tipos de plantas, mas nenhuma tendência consistente foi detectada entre as variáveis avaliadas. Segundo Jones e Jones (1974), o pH do solo menor do que 5,5 aumenta muito mais a concentração do alumínio (Al) do que do ferro $(\mathrm{Fe})$ na solução do solo, e este desequilíbrio provoca crescimento irregular das raízes, fragilizando o estádio nutricional da planta. Contradizendo este estudo, Nyczepir et al. (1985) concluíram que o $\mathrm{pH}$ do solo não foi correlacionado à ocorrência de morte precoce nos pomares da Geórgia, onde o pH variou entre 4,4 e 6,7, nos pomares sintomáticos, e entre 4,5 e 6,2, nos pomares assintomáticos; e da Carolina do Sul com variação entre 4,9 e 6,8 , nos pomares sintomáticos, e entre 5,0 e 6,8 , nos pomares assintomáticos. Embora seja mais comum a ocorrência da morte precoce em áreas previamente cultivadas com pessegueiro (RITCHIE; CLAYTON, 1981), estudos comprovaram que a síndrome pode ocorrer em pomares cujas áreas nunca foram cultivadas com a cultura (NYCZEPIR, 1990; NYCZEPIR; OKIE, 1996).

Os solos do Rio Grande do Sul, em seu estado natural, são predominantemente ácidos (CQFS RS/ SC, 2004) e, sabendo-se que ocorre variabilidade espacial da fertilidade do solo no mesmo pomar de pessegueiro (ROSTIROLLA et al., 2010), formulou-se a hipótese de que baixos níveis de $\mathrm{pH}$ e fertilidade do solo podem estar associados às plantas sintomáticas de morte precoce do pessegueiro. $\mathrm{O}$ objetivo deste trabalho foi avaliar a associação da morte precoce do pessegueiro com a fertilidade do solo.

\section{MATERIAL E MÉTODOS}

Amostras da rizosfera foram colhidas em nove pomares comerciais de pessegueiro, coletadas nos municípios de Pelotas e Canguçu, no sul do Estado do Rio Grande do Sul, entre os dias 15 de 
agosto e 13 de setembro de 2013. As principais características desses pomares, como localização, altitude mínima e máxima, sentido da declividade do terreno, cultivar-copa, porta-enxerto e idade das plantas são apresentadas na Tabela 1. Os pomares amostrados apresentavam área entre 0,3 e 1,5 ha e encontravam-se dentro da mesma gleba homogênea das respectivas propriedades rurais. Durante o período de amostragem, as plantas com sintomas de morte precoce puderam ser facilmente identificadas por meio dos sintomas típicos da síndrome (BRITTAIN; MILLER Jr., 1978; CAMPOS et al., 1998).

Uma amostra simples por planta foi colhida, na profundidade de 0 a $20 \mathrm{~cm}$, com auxílio de enxadão (CQFS RS/SC, 2004), à distância aproximada de $0,5 \mathrm{~m}$ do tronco das plantas. A amostragem foi sempre realizada na parte de baixo da fileira de plantio, totalizando 54 amostras provenientes de plantas sintomáticas e 54 amostras de plantas assintomáticas. As plantas assintomáticas e sintomáticas localizavam-se lado a lado (pareadas) na mesma linha de plantio e distanciavam 1,5 a $3 \mathrm{~m}$ entre si. Eventualmente, não foi possível encontrar plantas adequadas para amostragem na mesma linha de plantio, sendo então utilizada uma planta adjacente na linha de plantio ao lado, cujos pontos de amostragem assintomática $x$ sintomática distaram 4 a 6 metros. As amostras de solo foram embaladas em sacos plásticos e identificadas com números em ordem crescente, sendo ímpares as amostras provenientes de plantas assintomáticas e pares as oriundas das plantas sintomáticas.

No Laboratório de Fertilidade do Solo, da Embrapa Clima Temperado, em Pelotas-RS, realizaram-se as análises químicas completas das amostras, de acordo com metodologias definidas por CQFS RS/SC (2004). As variáveis analisadas foram: 1) $\mathrm{pH}$ do solo em água; 2) índice SMP; 3) acidez potencial $(\mathrm{H}+\mathrm{Al})$; 4) Al trocável; 5) Ca trocável; 6) $\mathrm{Mg}$ trocável; 7) $\mathrm{K}$ trocável; 8) saturação por $\mathrm{Al}$ (m); 9) saturação por bases (V); 10) classe textural; 11) teor de argila; 12) teor de matéria orgânica; 13) P extraível; 14) K extraível; 15) Na trocável; 16) S; 17) capacidade de troca de cátions (CTC) efetiva; 18) capacidade de troca de cátions (CTC) a pH 7,0; 19) $\mathrm{B}$;20) $\mathrm{Cu}$; 21) $\mathrm{Zn}$; 22) Mn; e 23) Fe.

A análise estatística dos dados foi realizada em duas etapas. Na primeira, buscou-se avaliar, conjuntamente, todas as variáveis observadas mediante uma análise discriminante (SAS 9.2. SAS Institute Inc., Cary, NC, USA). Esta técnica permite classificar as plantas da amostra em dois grupos predefinidos: sintomáticas e assintomáticas. Também verificaram-se as semelhanças entre as variáveis observadas em cada um dos grupos estabelecidos a priori, mediante análise de agrupamento (MINITAB Release 14 Inc. Statistical software). Na segunda etapa, as variáveis foram investigadas individualmente, através de análise de variância, para identificar aquelas que evidenciavam diferença significativa entre os grupos sintomáticos e assintomáticos (MORRISON, 1976; MINGOTI, 2007).

\section{RESULTADOS E DISCUSSÃO}

Os valores de $\mathrm{pH}$ em água dos solos dos Estados do Rio Grande do Sul e de Santa Catarina são classificados em quatro níveis, para fins de interpretação: muito baixo $(\leq 5,0)$, baixo $(5,1$ a 5,4$)$, médio $(5,5$ a 6,0$)$ e alto $(>6,0)$ (CQFS RS/SC, 2004). Segundo esta classificação, do total das 108 amostras analisadas no presente trabalho, apenas 07 amostras $(6,48 \%)$ apresentaram $\mathrm{pH}$ alto, tendo sido coletadas em apenas dois pomares, os denominados como $\mathrm{n}^{\text {os }}$ 3 e 6 (Tabela 2).

Observou-se que houve predomínio das classes mais baixas de $\mathrm{pH}$ do solo, em ambos os tipos de plantas amostradas. As amostras provenientes da rizosfera de plantas assintomáticas apresentaram a seguinte distribuição: muito baixo $(35,19 \%)$, baixo $(33,33 \%)$, médio $(25,93 \%)$ e alto $(5,56 \%)$. Nas plantas sintomáticas, a interpretação do $\mathrm{pH}$ das amostras foi: muito baixo $(37,04 \%)$, baixo $(29,63 \%)$, médio $(25,93 \%)$ e alto $(7,41 \%)$. A recomendação de pH ideal para a cultura do pessegueiro é 6,0 (CQFS $\mathrm{RS} / \mathrm{SC}, 2004$ ), ou seja, a maioria das amostras apresentou $\mathrm{pH}$ abaixo do recomendado para a cultura, contribuindo para a inadequada nutrição das plantas. Observou-se que o $\mathrm{pH}$ do solo entre duas plantas vizinhas, sintomática e assintomática, apresentou variação de, no máximo, 0,8. Considerando-se todas as amostras assintomáticas e sintomáticas de cada pomar, separadamente, constatou-se que a amplitude do $\mathrm{pH}$ do solo foi de 0,4 , com variação entre 4,8 e 5,2 (pomar $\left.n^{\circ} 9\right)$, até 1,5 , com variação entre 4,4 e 5,9 (no pomar $n^{\circ} 4$ ) (Tabela 2).

Do ponto de vista de fertilidade do solo, constatou-se que o $\mathrm{pH}$ médio dos pomares foi de 5,22 , as saturações de alumínio e de bases de 24,2 e $40,9 \%$, respectivamente, e os teores de $\mathrm{P}$ e K, de 18,8 e $108,4 \mathrm{mg} \cdot \mathrm{dm}^{-3}$, respectivamente (Tabela 2 ). Porém, constatou-se grande variação para essas variáveis; por exemplo, para o $\mathrm{pH}$, os valores variaram de 4,10 a 6,40 , sendo que apenas $15,7 \%$ das 108 amostras apresentaram valores na classe de 5,83-6,40 (Tabela 3 ), e apenas 11 amostras apresentaram $\mathrm{pH} \geq 6,0$. Os pomares $n^{\text {os }} 3$ e 6 apresentaram, em média, os 
maiores valores de $\mathrm{pH}$ (Tabelas 2 e 4). No entanto, poucas amostras apresentaram valores superiores ao recomendado, com cinco amostras no pomar $\mathrm{n}^{\circ} 3 \mathrm{e}$ seis no pomar $n^{\circ} 6$. A partir desses dados, constatouse a necessidade da realização de calagem em 84,3\% dos pomares avaliados (Tabela 2).

A falta de calagem interfere diretamente em outras duas variáveis avaliadas: a saturação por alumínio $(m)$ e a saturação por bases (V). Nesse sentido, $48,1 \%$ dos pomares apresentaram $m$ superior a $9,86 \%$, valor próximo a $10,0 \%$, considerado tóxico para a maioria das espécies de plantas. Ao mesmo tempo, $75 \%$ das amostras apresentaram $\mathrm{V}<65,0 \%$ (Tabela 3), saturação considerada adequada para a maioria das espécies de plantas. Os pomares n ${ }^{\circ s} 3$ e 6 apresentaram os menores valores de $m$ e, ao mesmo tempo, os maiores valores de V (Tabela 4). Por outro lado, os pomares $\mathrm{n}^{\text {os }} 2,8$ e 9 apresentaram maiores valores de $m$ e menores de $\mathrm{V}$, indicando a necessidade de calagem nesses pomares (Tabela 4).

Sharpe e Reilly (1986), contrariando estudos anteriores (BRITTAIN; MILLER Jr., 1978; RITCHIE; CLAYTON, 1981), concluíram que o pH do solo não foi um fator importante na manifestação dos sintomas da síndrome, pois o mesmo variou de 5,1 a 6,1 , nas plantas sintomáticas, e de 5,0 a 6,4 nas plantas sadias.

Com relação à matéria orgânica, $87,04 \%$ das amostras provenientes de plantas assintomáticas apresentaram baixa porcentagem de matéria orgânica com índice $\leq 2,5 \%$; e 12,96\% das amostras apresentaram valores médios, entre 2,6 e 5,0\%. Para as amostras provenientes de plantas sintomáticas, a interpretação foi semelhante, e $85,19 \%$ situaram-se na classe baixa e $14,81 \%$ na classe média. Nenhuma amostra foi classificada na classe alta de matéria orgânica (valores $>5,0 \%$ ).

Em relação ao fósforo, $56,5 \%$ das amostras apresentaram valores dentro das classes baixo e muito baixo (Tabela 3 ) com destaque para os pomares $\mathrm{n}^{\text {os }} 2,3,4,5$ e 8 (Tabela 4). Teores de fósforo na classe muito alto ocorreram em $31,5 \%$ das amostras (Tabela 3 ), com destaque para os pomares nos 9,7 e 6 (Tabela 4). Especificamente no caso do pomar $n^{\circ} 9$, todas as doze amostras apresentaram valores acima do limite superior da classe muito alto (Tabela 4), sendo que, em média, o teor de $\mathrm{P}$ foi 1,75 vez maior do que o limite máximo dessa classe $\left(24,0 \mathrm{mg} \mathrm{dm}^{-3}\right)$. Para o pomar $\mathrm{n}^{\circ} 7$, oito amostras apresentaram valores maiores que o limite superior, sendo que, em média, o teor de $\mathrm{P}$ foi 1,9 vez maior do que o limite máximo da classe muito alto (Tabela 4).

Para o potássio, apenas $4,6 \%$ das amostras apresentaram teores na classe baixo e $75,9 \%$ apresentaram teores nas classes alto e muito alto (Tabela 3), indicando que este nutriente tem sido aplicado com frequência nos pomares avaliados. Dentro da classe muito alto (33,3\% das amostras, Tabela 3), verificaram-se 11 amostras com valores superiores a $200,0 \mathrm{mg} \mathrm{dm}^{-3}$, concentração elevada e que pode interferir negativamente na relação com os elementos $\mathrm{Ca}$ e $\mathrm{Mg}$. Os pomares n ${ }^{\text {os }} 7$ e 6 destacaramse nesse sentido e apresentaram nove e duas de suas amostras, respectivamente, com $\mathrm{K}$ acima de 200,0 $m g \mathrm{dm}^{-3}$ (Tabela 2).

Analisando conjuntamente as variáveis de fertilidade do solo, o pomar $n^{\circ} 6$ apresentou melhor equilíbrio entre nutrientes, enquanto o pomar $n^{\circ}$ 2 , o pior. Constatou-se ainda que o pomar $\mathrm{n}^{\circ} 7$ apresentou teores de $\mathrm{Pe} \mathrm{K}$ elevados, porém $\mathrm{pH}$ muito baixo, elevada $m$ e baixa V (Tabelas 2 e 4). A falta de calagem indica que, no pomar $\mathrm{n}^{\circ} 7$, apesar dos teores adequados de $\mathrm{Pe} \mathrm{K}$, a eficiência de uso desses nutrientes será baixa.

Como resultado da análise discriminante dos dados, não foi possível estabelecer uma função matemática adequada, chamada de regra de classificação ou discriminação. A função discriminante linear de Fisher foi determinada para 99 dados amostrais e, depois, testada para 9 amostras sorteadas com cerca de $10 \%$ do total dos dados. $\mathrm{Na}$ validação da função, o percentual de classificação errônea foi de $42 \%$, ou seja, 5 das 9 amostras foram classificadas de forma inadequada. A correlação entre as variáveis e a função discriminante demonstrou não haver correlação significativa entre elas, fato que auxilia na explicação do baixo índice de acerto.

$\mathrm{Na}$ verificação da semelhança entre as variáveis em cada grupo estabelecido a priori, observou-se que a estrutura de similaridade entre elas é praticamente a mesma, salvo alguma pequena diferença na escala. Isso pode ser verificado pela Figura 1A com o dendrograma de todas as plantas do estudo; Figura 1B com o dendrograma das variáveis considerando as plantas assintomáticas; e Figura 1C com o dendrograma das variáveis considerando as plantas sintomáticas. A variável "sintoma" - a mais importante para estabelecer a discriminação - não apresentou semelhança significativa com as demais variáveis, fato que contribuiu para elevar a taxa de classificação errônea das plantas.

Como a análise conjunta das variáveis não permitiu estabelecer uma avaliação dos grupos sintomáticos e assintomáticos, partiu-se para a análise univariada dos dados. A ANOVA realizada para cada variável mostrou não haver diferença significativa entre esses dois grupos ao nível de $5 \%$ de probabilidade. Esta avaliação evidencia 
que as variáveis, tanto conjuntamente quando individualmente, não proporcionam a separação dos grupos, ou seja, os valores individuais das variáveis são muito parecidos para os grupos, assim como suas médias (Tabela 5).

Os resultados obtidos neste trabalho permitiram verificar que as características químicas do solo coletado sob a copa de plantas sintomáticas e assintomáticas de morte precoce não explicam, por si só, a ocorrência da síndrome, o que reforça a hipótese da existência de porta-enxertos tolerantes à morte precoce do pessegueiro (MAYER et al., 2009). Os dados deste trabalho concordam com alguns estudos realizados no sudeste dos Estados Unidos (SHARPE; REILLY, 1986; NYCZEPIR et al., 1985), que também ficou evidenciado que os níveis de nutrientes e os valores de $\mathrm{pH}$ do solo não foram correlacionados às plantas sintomáticas de morte precoce.

Nos pomares amostrados, plantas com sintomas de decrepitude ocorreram independentemente, tanto entre as 11 cultivares-copa como nas diferentes idades das plantas, entre os dois e oito anos (Tabelas 1 e 2). Assim, outros fatores que não a fertilidade do solo (apesar de, como referido anteriormente, alguns pomares apresentarem níveis muito baixos de nutrientes e muito altos de alumínio tóxico) estão influenciando na mortalidade de plantas. Dentre os possíveis fatores, a variabilidade genética dos porta-enxertos, com o uso de caroços de cultivares-copa obtidos nas indústrias de conservas, e as características físicas do solo, como a textura, a profundidade e a umidade, são os mais importantes. Para o primeiro fator, é sabido que o método de propagação de pessegueiros mais usado no Sul do Rio Grande do Sul utiliza, como porta-enxerto, misturas de caroços de diversas cultivares- copa provenientes das indústrias processadoras, as quais não apresentam características desejáveis de portaenxerto, favorecendo a ocorrência de problemas no desenvolvimento das plantas e interferindo na longevidade dos pomares (MAYER et al., 2009). Em relação ao segundo fator, os solos predominantes dessa região, classificados como Argissolos, caracterizam-se por serem rasos e apresentarem acúmulo de argila no horizonte B (CUNHA et al., 2006; STRECK et al., 2008). Tais características impedem ou dificultam o desenvolvimento radicular das plantas, seu adequado estabelecimento no solo e, ao mesmo tempo, dificulta a percolação da água da chuva, ocasionando o surgimento de zonas de elevada umidade. Assim como a fertilidade, as variáveis físicas do solo apresentam elevada variabilidade espacial e podem interferir diretamente sobre o desenvolvimento das plantas. No caso dos pomares amostrados no presente trabalho, é possível que a variabilidade genética dos porta-enxertos possa estar interagindo com a variabilidade espacial das características físicas de solo e contribuindo para a mortalidade das plantas, já que não foi constatada relação entre este sintoma com os atributos químicos de fertilidade do solo. 
TABELA 1-Identificação, localização e principais características dos nove pomares de pessegueiro amostrados. Embrapa Clima Temperado, 2014.

\begin{tabular}{ccccccc}
\hline Pomar & Localização & $\begin{array}{c}\text { Altitude } \\
(\text { metros })\end{array}$ & $\begin{array}{c}\text { Sentido da } \\
\text { declividade } \\
\text { do terreno }\end{array}$ & Cultivar-copa & Porta-enxerto & $\begin{array}{c}\text { Idade } \\
\text { (anos) }\end{array}$ \\
\hline Pomar 1 & $\begin{array}{c}\text { Colônia Santa Áurea, } \\
7^{\circ} \text { distrito de Pelotas }\end{array}$ & $156-167$ & N e NW & Bonão & $\begin{array}{c}\text { mistura de caroços } \\
\text { de cultivares } \\
\text { copa obtidas } \\
\text { nas indústrias } \\
\text { conserveiras }\end{array}$ & 05 \\
\hline Pomar 2 & $\begin{array}{c}\text { Colônia Santa Áurea, } \\
7^{\circ} \text { distrito de Pelotas }\end{array}$ & $141-152$ & S & Bonão & idem & 03 \\
\hline Pomar 3 & $\begin{array}{c}\text { Colônia São Manoel, } \\
8^{\circ} \text { distrito de Pelotas }\end{array}$ & $242-248$ & NW & Bonão & idem & 05 \\
\hline Pomar 4 & $\begin{array}{c}\text { Colônia Dias, } \\
7^{\circ} \text { distrito de Pelotas }\end{array}$ & $117-123$ & SE & Sensação & idem & 08 \\
\hline Pomar 5 & $\begin{array}{c}\text { Colônia Santa Eulália, } \\
5^{\circ} \text { distrito de Pelotas }\end{array}$ & $144-148$ & NE & Maciel e Jade & idem & 02 \\
\hline Pomar 6 & $\begin{array}{c}\text { Colônia Santa Helena, } \\
8^{\circ} \text { distrito de Pelotas }\end{array}$ & $206-213$ & N & $\begin{array}{c}\text { Chiripá, Granada, } \\
\text { Chimado e }\end{array}$ & idem & 04 \\
\hline Pomar 7 & $\begin{array}{c}\text { Colônia Santa Helena, } \\
8^{\circ} \text { distrito de Pelotas }\end{array}$ & $225-233$ & SW & Jade & idem & 03 \\
\hline Pomar 8 & $\begin{array}{c}\text { Colônia Santa Clara, } \\
1^{\circ} \text { distrito de Canguçu }\end{array}$ & $302-325$ & W & Granito & idem & 05 \\
\hline Pomar 9 & $\begin{array}{c}\text { Colônia Rincão dos Maias, } \\
1^{\circ} \text { distrito de Canguçu }\end{array}$ & $250-260$ & NE & Esmeralda & idem & 04 \\
\hline
\end{tabular}

${ }^{1} \mathrm{~N}=$ norte $\mathrm{S}=$ sul; $\mathrm{W}=$ oeste $\mathrm{NW}=$ noroeste $\mathrm{NE}=$ nordeste; $\mathrm{SW}=$ sudoeste; $\mathrm{SE}=$ sudeste. 

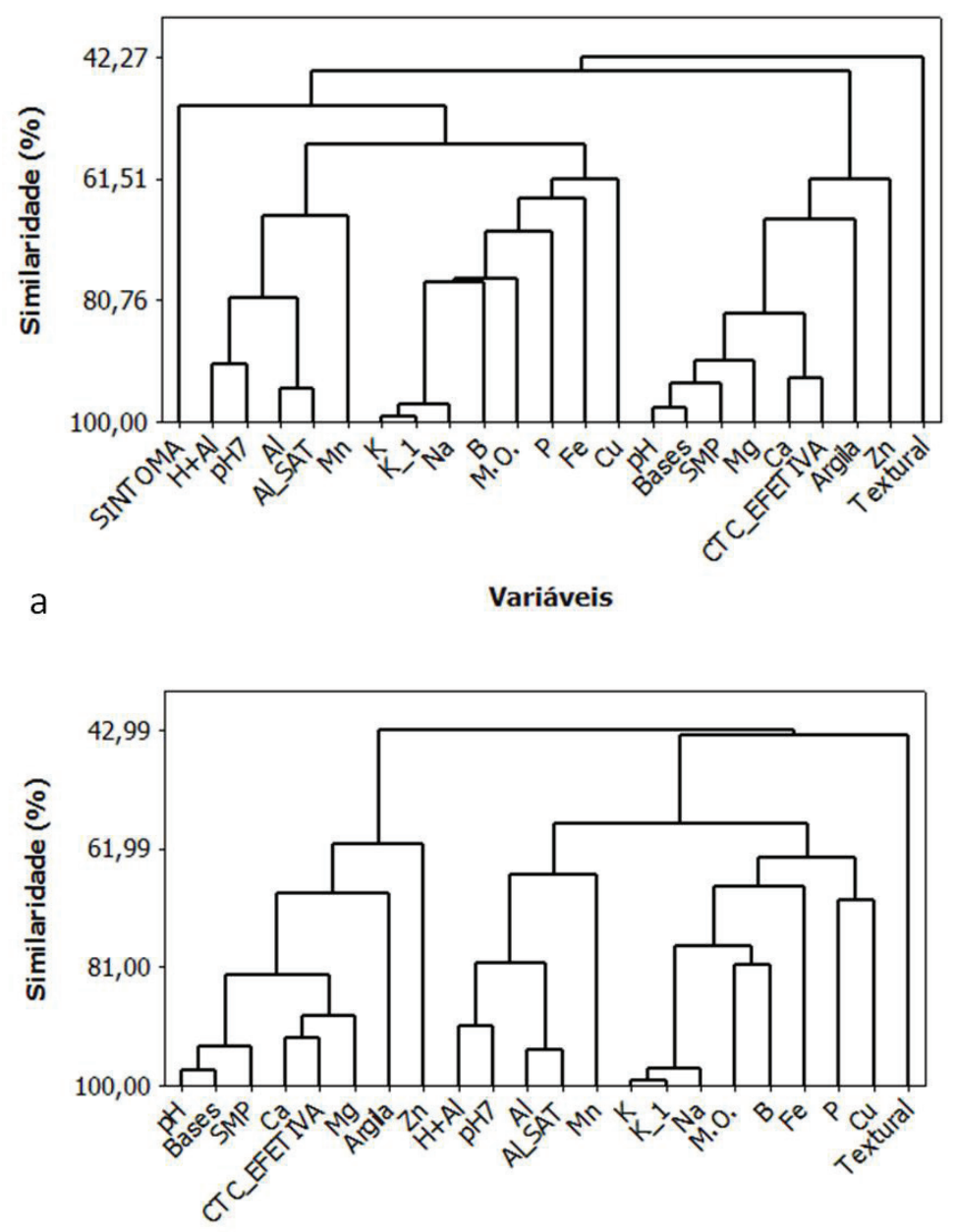

b

Variáveis

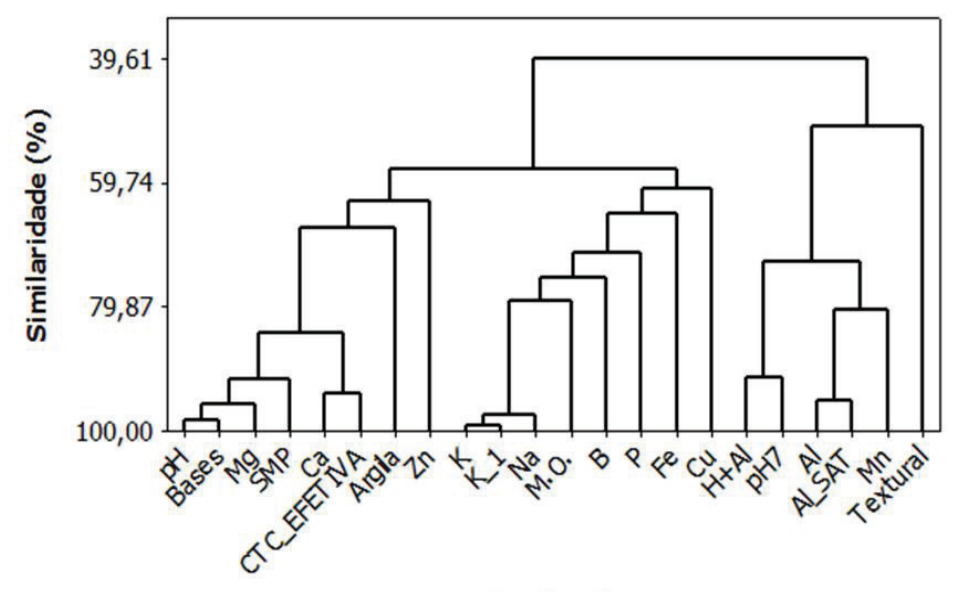

C

Variáveis

FIGURA 1- Análise de agrupamento entre as variáveis observadas, pelo método da Ligação Média, provenientes das amostras coletadas da rizosfera de: a) todas as plantas sintomáticas e assintomáticas; b) plantas assintomáticas; c) plantas sintomáticas. Embrapa Clima Temperado, 2014. 


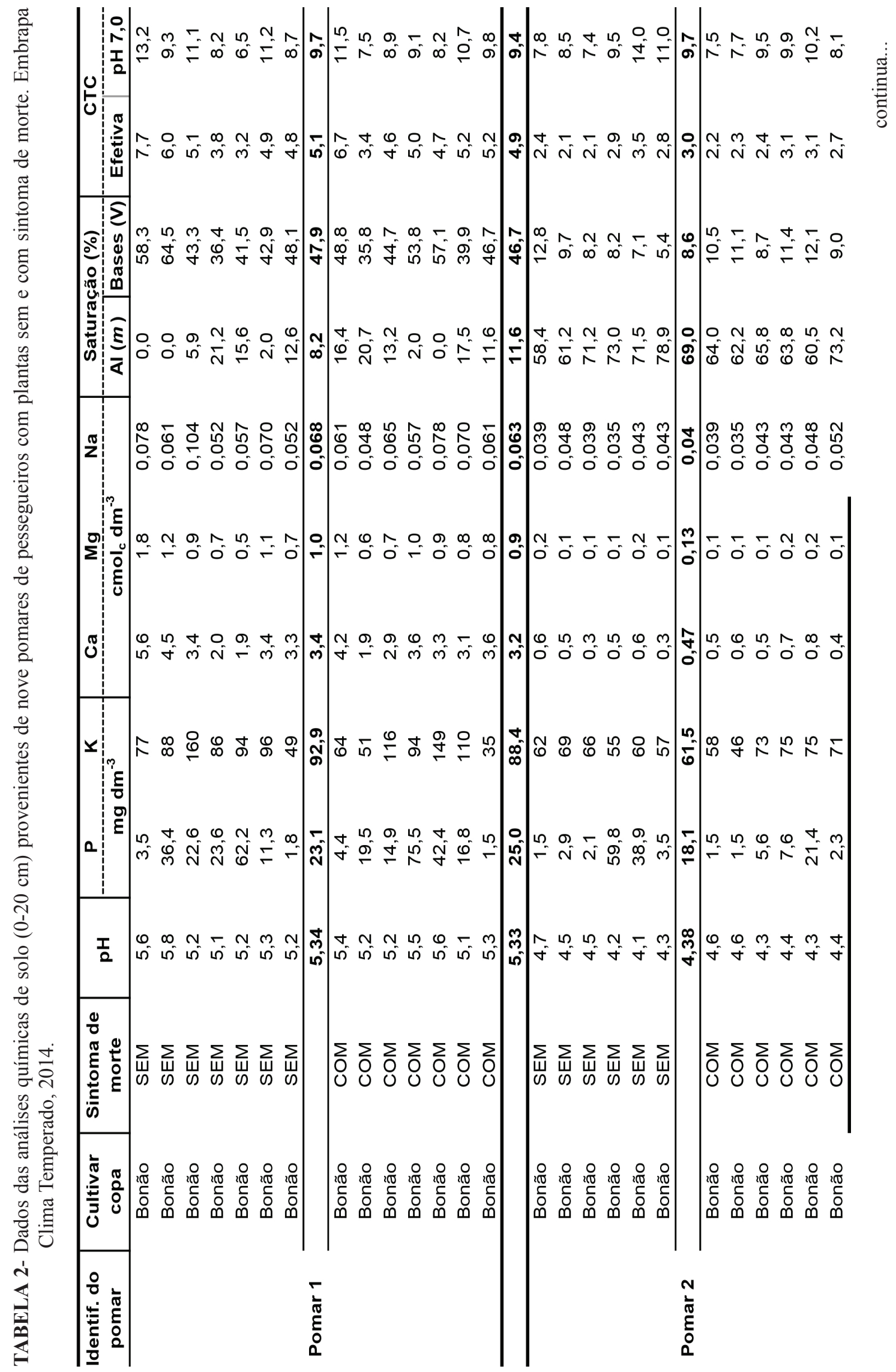

Rev. Bras. Frutic., Jaboticabal - SP, v. 37, n. 3, p. 773-788, Setembro 2015 


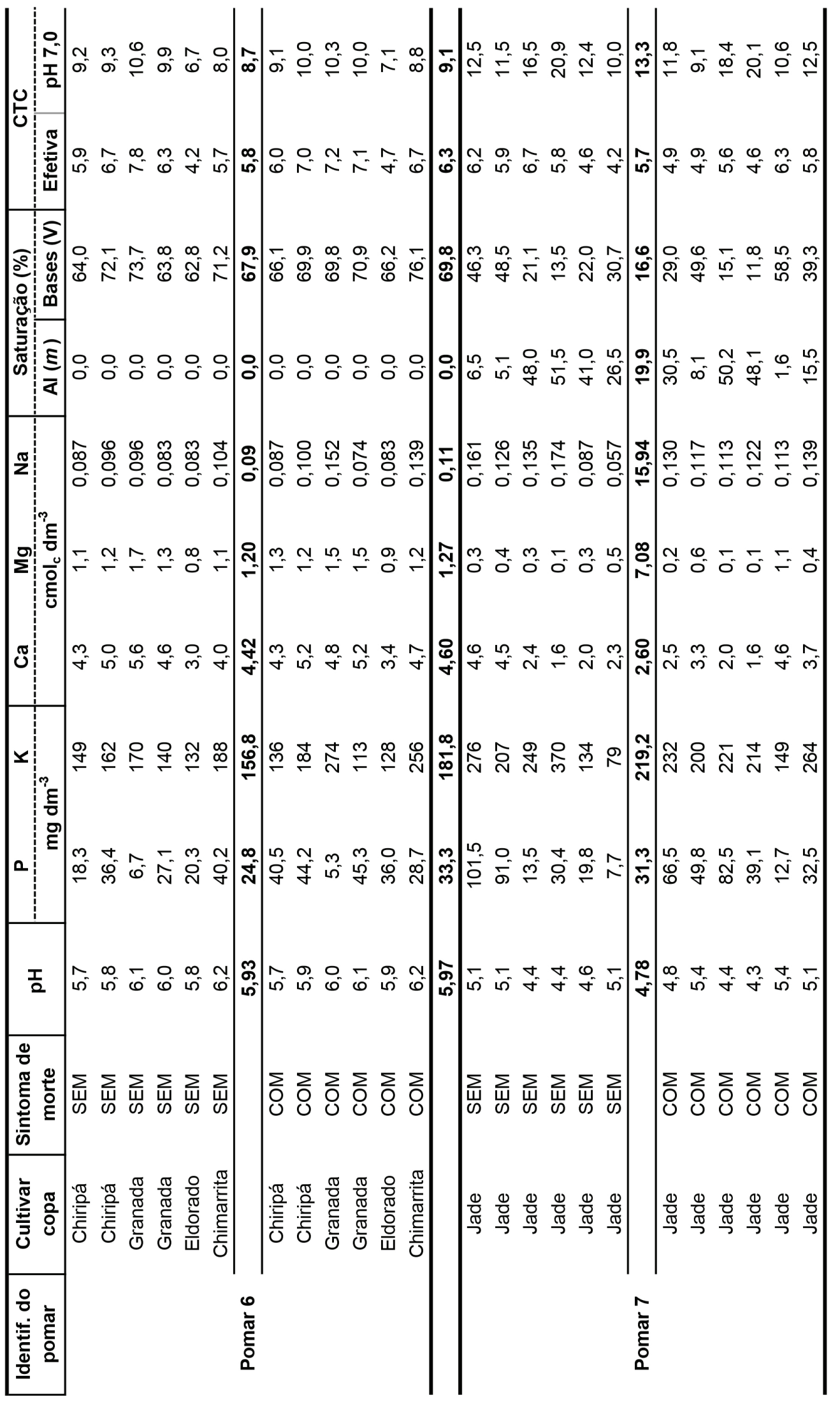




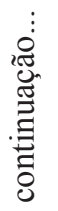

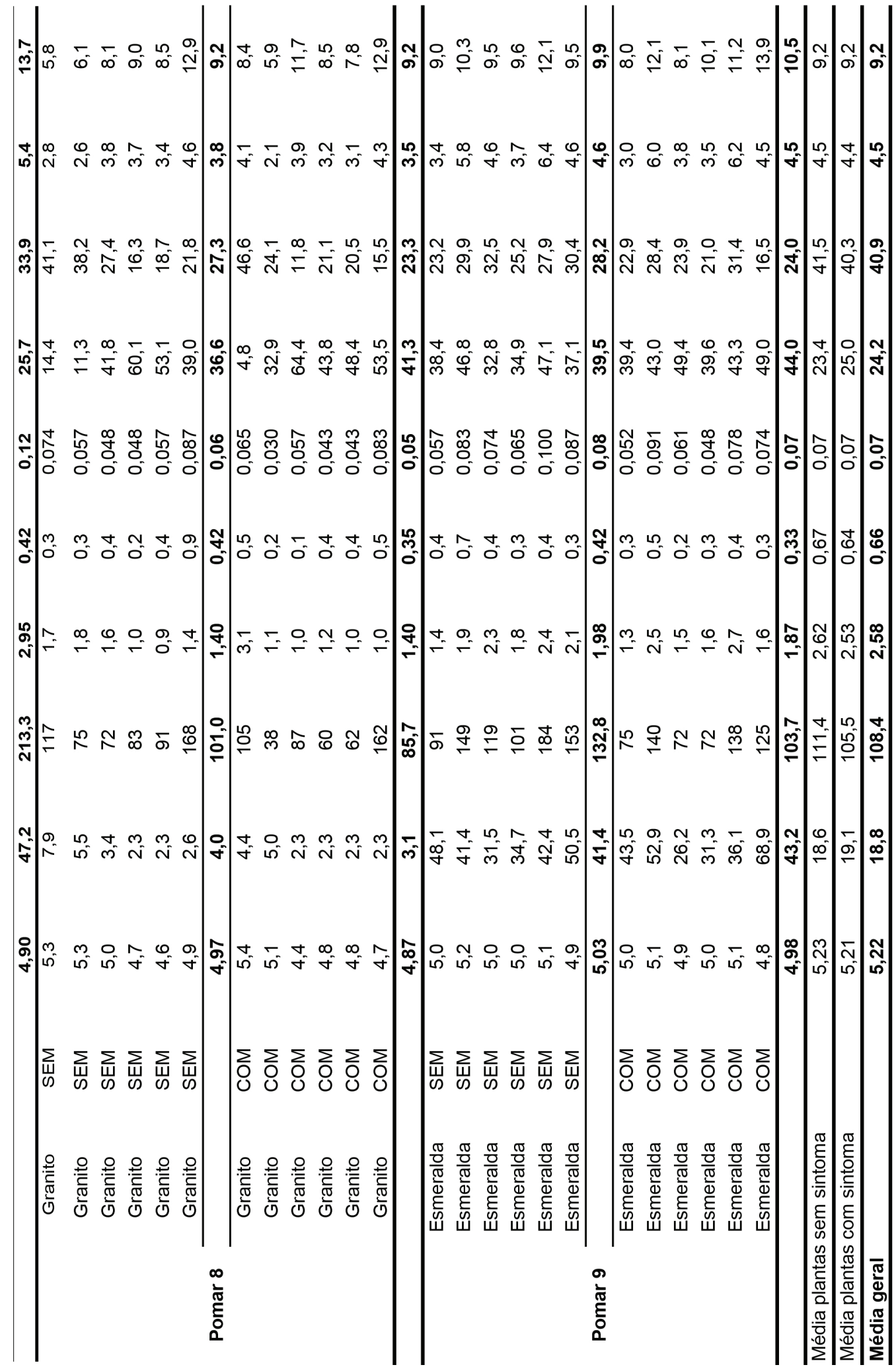




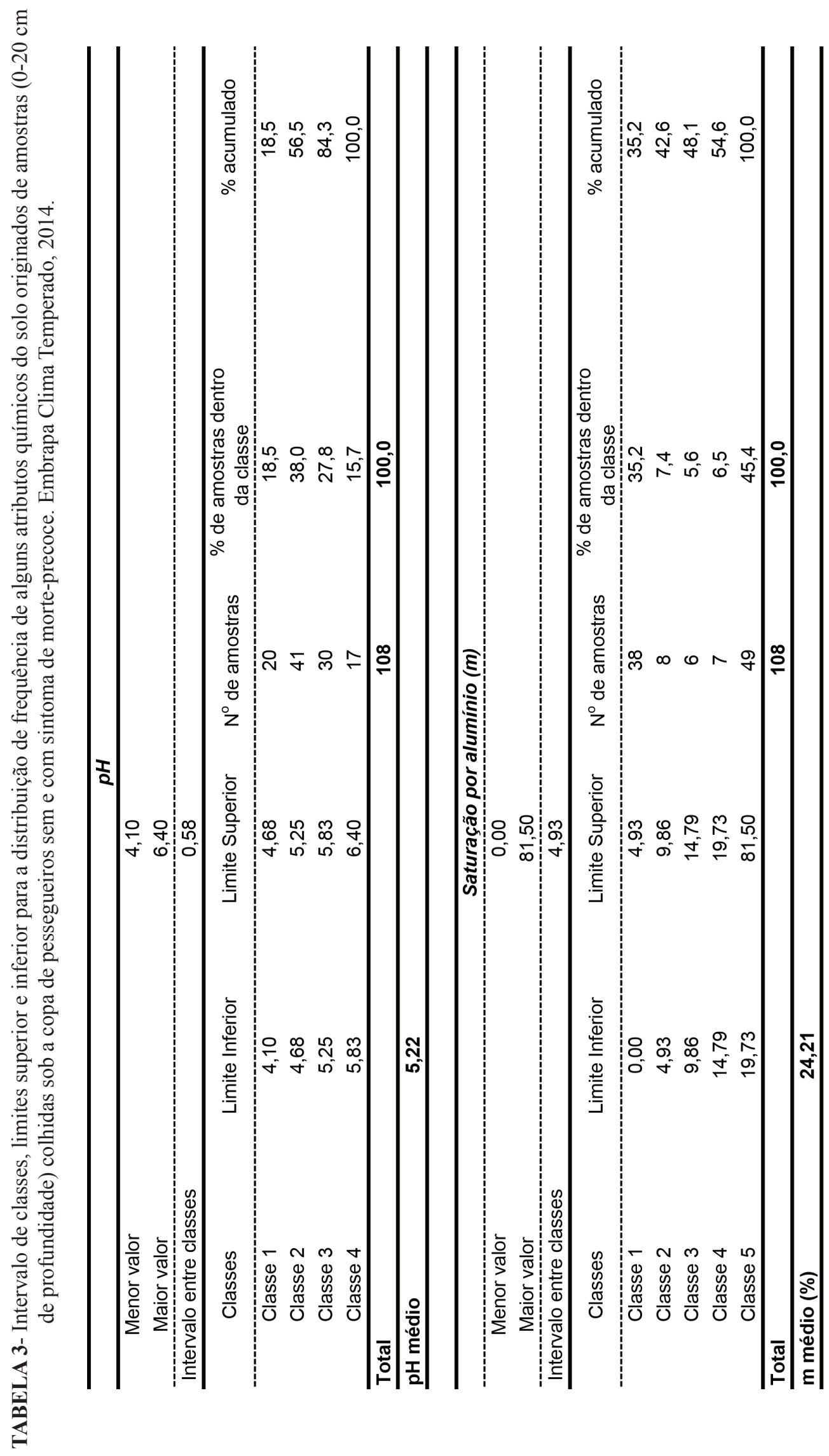




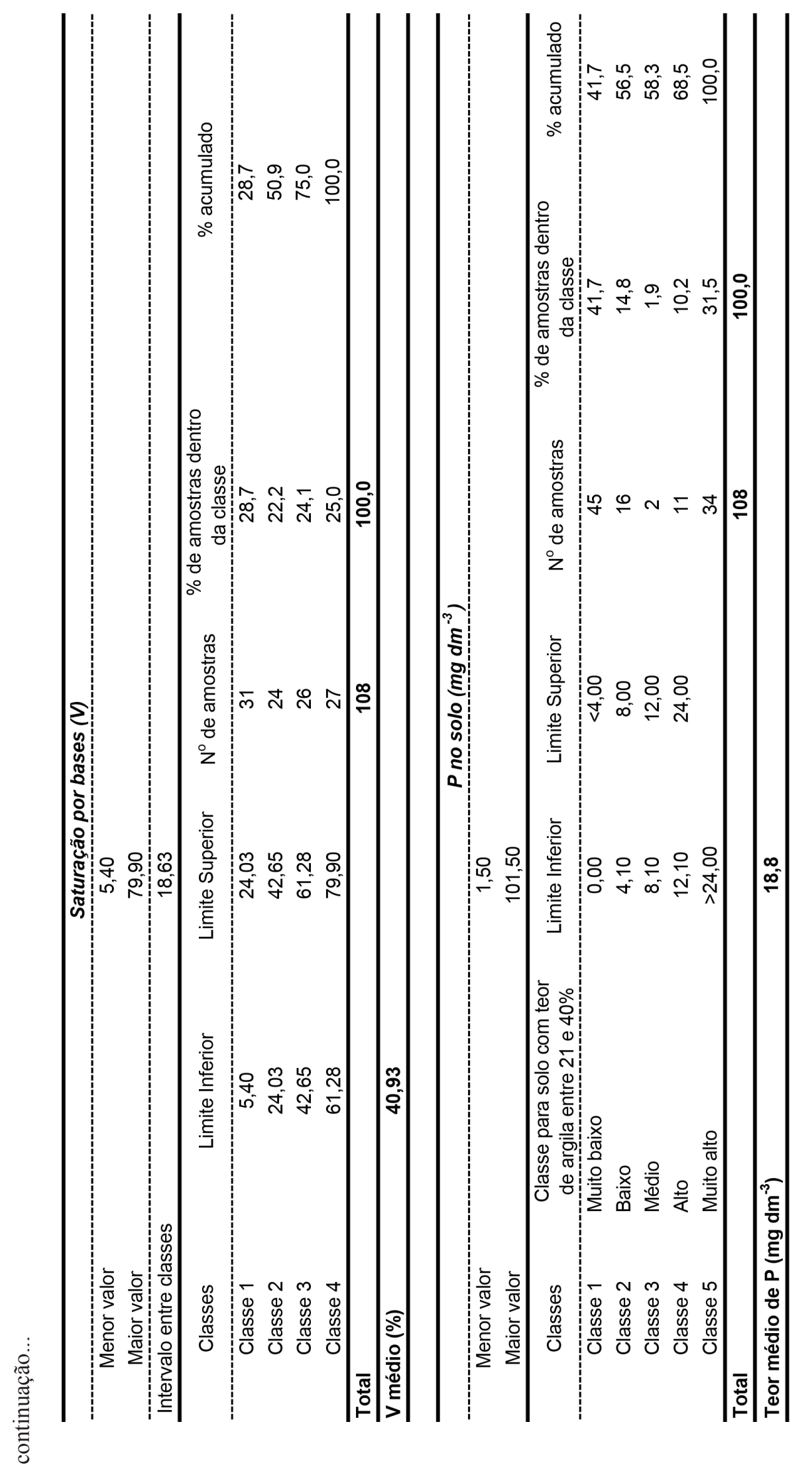

Rev. Bras. Frutic., Jaboticabal - SP, v. 37, n. 3, p. 773-788, Setembro 2015 


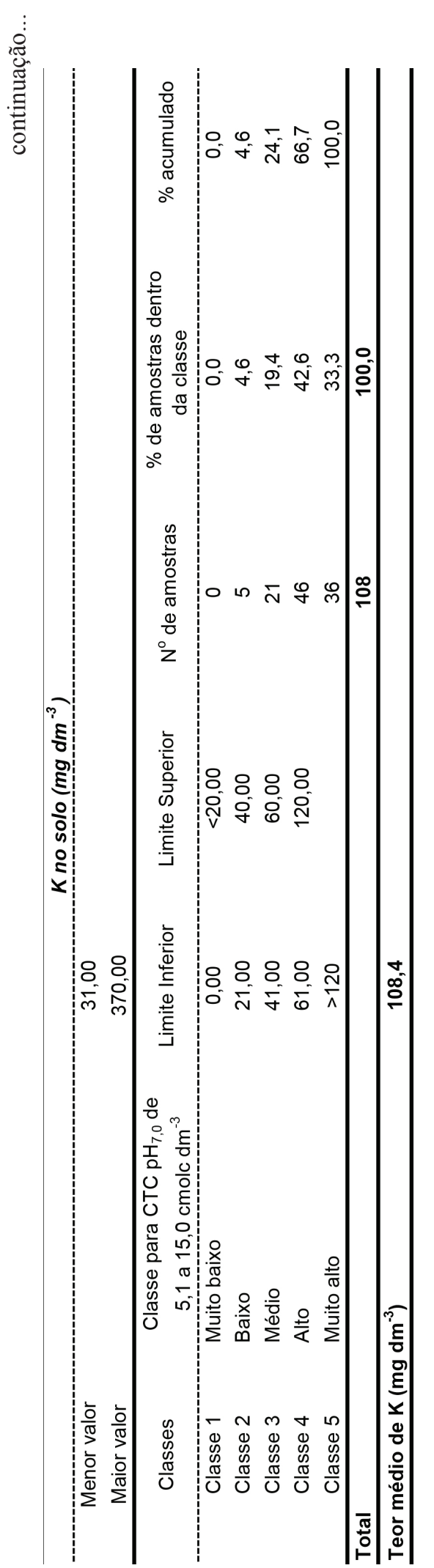

क्ष

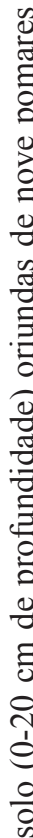

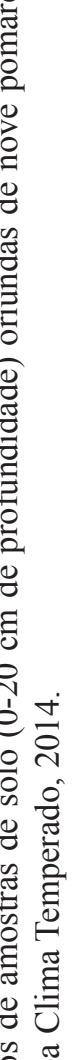

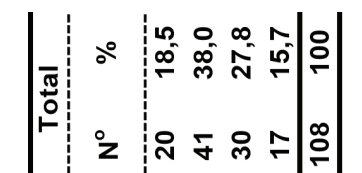

| \begin{tabular}{l|l|l} 
& & \\
\hline & 0 & \\
\hline & 0
\end{tabular}

o)

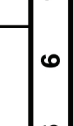

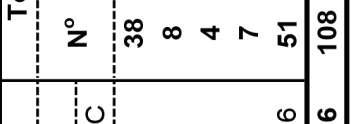

$\begin{array}{c:c:c}0 & 0 & 0 \\ 0 & 0-2- & 0 \\ & 0 & 0\end{array}$

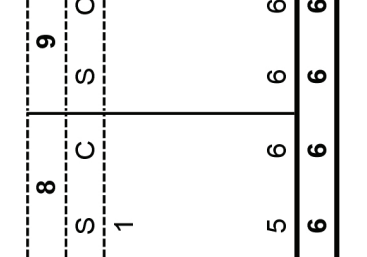

$0,0,0 n$
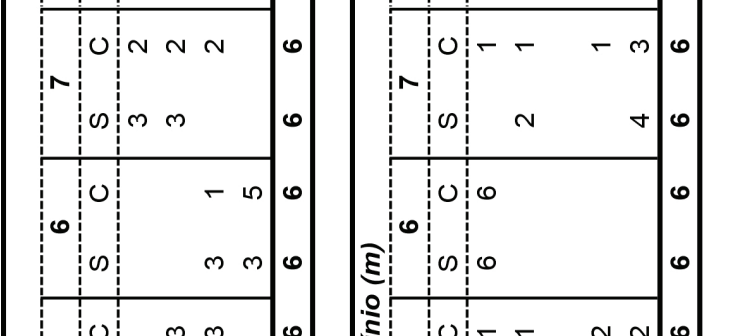

\begin{tabular}{ll:l|l|l}
0 & 0 \\
0 & 0 & 0 & 0
\end{tabular}

공

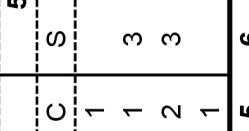

\section{(a)}

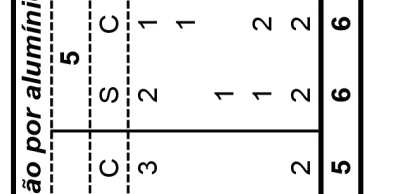

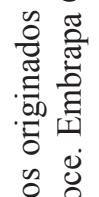
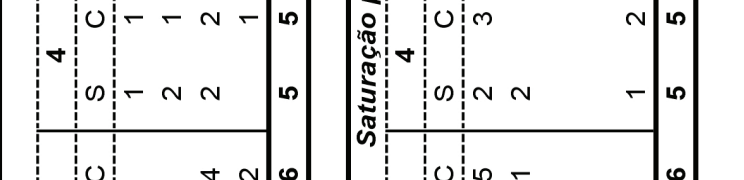

青苛

$\begin{array}{lll}0 & \\ 0 & 0 \\ 0 & 0 \\ 0 & 0 & 0 \\ 0 & 0 & 0\end{array}$

过

党

ॠृ:

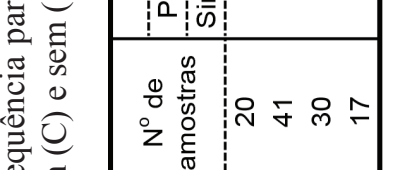

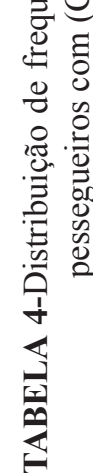
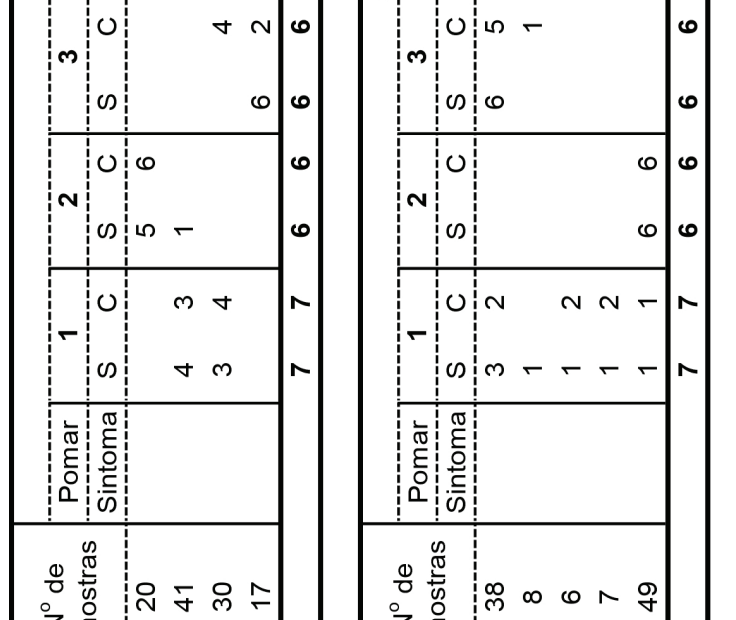

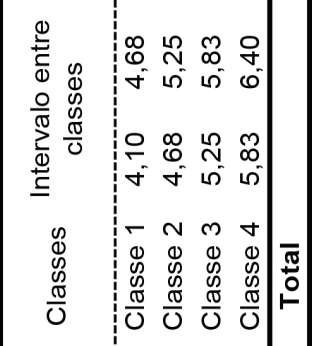

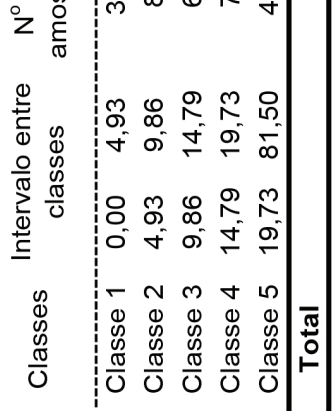




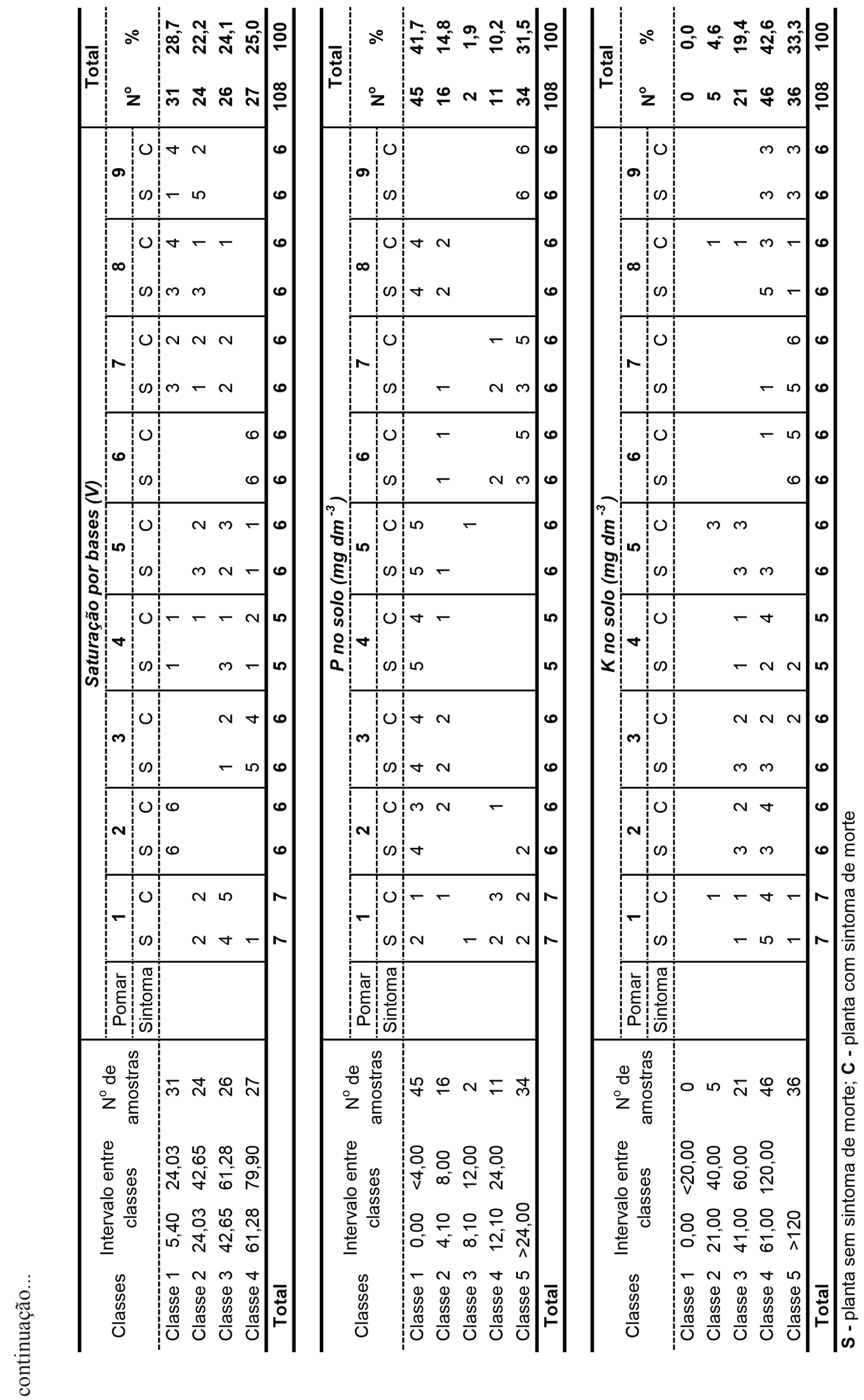


TABELA 5- Análise de variância univariada das variáveis químicas do solo provenientes de pessegueiros assintomáticos e sintomáticos de morteprecoce. Embrapa Clima Temperado, 2014.

\begin{tabular}{cc}
\hline Variável & P-valor \\
\hline $\mathrm{pH}$ & 0,9499 \\
$\mathrm{H}+\mathrm{Al}$ & 0,9554 \\
$\mathrm{Al}$ & 0,9683 \\
$\mathrm{Ca}$ & 0,8190 \\
$\mathrm{Mg}$ & 0,9517 \\
$\mathrm{~K}$ & 0,6883 \\
$\mathrm{P}$ & 0,9527 \\
$\mathrm{Na}$ & 0,6071 \\
Saturação por Al $(m)$ & 0,8825 \\
Saturação por bases $(\mathrm{V})$ & 0,8842 \\
$\mathrm{CTC}_{\text {eftiva }}$ & 0,7438 \\
$\mathrm{CTC}_{\mathrm{pH}} \mathrm{i}, 0$ & 0,9345 \\
\hline
\end{tabular}

\section{CONCLUSÕES}

A maioria dos pomares estudados apresenta algum problema em relação aos atributos de fertilidade do solo e, em $84,3 \%$ das amostras, há a necessidade de realizar calagem adequada para a cultura do pessegueiro.

De acordo com a metodologia multivariada de análise discriminante, a função encontrada não foi eficiente para distinguir o grupo de plantas sintomáticas e assintomáticas, pois a taxa de classificação errônea superou 40\%. Além dessa, a análise de variância individual identificou que, univariadamente, não existe diferença significativa na fertilidade do solo entre os dois grupos de plantas amostradas.

Embora a fertilidade do solo, na maioria dos pomares amostrados, esteja aquém do recomendado para a cultura do pessegueiro, a ocorrência da morte precoce do pessegueiro não apresentou relação com os atributos químicos de fertilidade do solo.

\section{AGRADECIMENTOS}

Os autores agradecem ao CNPq e à Embrapa, pelo suporte financeiro; aos escritórios Municipais da Emater em Pelotas-RS, e Canguçu-RS, pelo apoio, e a todas as famílias de persicultores que acompanharam e permitiram a realização deste trabalho.

\section{REFERÊNCIAS}

BRITTAIN, J.A.; MILLER Jr., R.W. Managing peach tree short life in the Southeast. Clemson: Agricultural Extension Services of Georgia, 1978. 19p. (Circular, 585).

CAMPOS, A.D.; CARNEIRO, R.M.D.G.; FINARDI, N.L.; FORTES, J.F. Morte precoce de plantas. In: MEDEIROS, C.A.B.; RASEIRA, M. do C.B. A cultura do pessegueiro. Brasília: Embrapa-SPI; Pelotas: Embrapa-CPACT, 1998. p.280-295.

CARNEIRO, R.M.D.G.; FORTES, J.F.; ALMEIDA, M.R.A. Associação de Criconemella xenoplax com a morte do pessegueiro no Rio Grande do Sul. Nematologia Brasileira, Brasília, v.17, n.2, p.122$131,1993$.

CQFS - Comissão de Química e Fertilidade do Solo (SBCS - CQFS RS/SC). Manual de adubação e de calagem para os Estados do Rio Grande do Sul e de Santa Catarina. 10. ed. Porto Alegre: Sociedade Brasileira de Ciência do Solo/Núcleo Regional Sul, 2004. 400p.

CUNHA, N.G.; SILVEIRA, R.J.C.; SEVERO, C.R.S. Solos e terras do planalto sul-riograndense e planícies costeiras. Pelotas: Embrapa Clima Temperado, 2006. 43p. (Circular Técnica, 55).

JONES, T.L.; JONES, U.S. Influence of soil $\mathrm{pH}$, aluminum and sulfur on short life of peaches trees growing on loamy sands in Southeastern United States. Florida State Horticultural Society, Lake Alfred, v.87, p.367-371, 1974. 
LUNA-GUERRERO, A.Y.; MONTES-BELMONT, R.; TALAVERA-RUBIA, M.F.; FLORESMOCTEZUMA, H.E.; BRAVO-LUNA, L. Estudio preliminar de los factores bióticos e abióticos asociados a la muerte del duraznero en Morelos, México. Nematropica, Auburn, v.41, n.2, p.254262, 2011.

MARAFON, A.C.; HERTER, F.G.; BACARIN, M.A.; HAWERROTH, F.J. Atividade da peroxidase durante o período hibernal de plantas de pessegueiro (Prunus persica (L.) Batsch.) cv. Jubileu com e sem sintomas da morte precoce. Revista Brasileira de Fruticultura, Jaboticabal, v.31, n.4, p.938-942, 2009.

MAYER, N.A.; UENO, B.; ANTUNES, L.E.C. Seleção e clonagem de porta-enxertos tolerantes à morteprecoce do pessegueiro. Pelotas: Embrapa Clima Temperado, 2009. 13p. (Comunicado Técnico, 209).

MAYER, N.A; UENO, B. A morte-precoce do pessegueiro e suas relações com porta-enxertos. Pelotas: Embrapa Clima Temperado, 2012. 42p. (Documentos, 359).

MINGOTI, S. A. Análise de dados através de métodos de estatística multivariada: uma abordagem aplicada. 2. ed. Belo Horizonte: UFMG, 2007. 295p.

MORRISON, D. F. Multivariate statistical methods. $2^{\text {nd }}$ ed. Tokyo: MacGraw-Hill Kogakusha, 1976. 415 p.

NYCZEPIR, A.P. Influence of Criconemella xenoplax and pruning time on short life of peach trees. Journal of Nematology, College Park, v.22, n.1, p.97-100, 1990.

NYCZEPIR, A.P.; BERTRAND, P.F.; MILLER, R.W.; MOTSINGER, R.E. Incidence of Criconemella spp. and peach orchard histories in short-life and nonshort-life sites in Georgia and South Carolina. Plant Disease, Saint Paul, v.69, n.10, p.874-877, 1985.

NYCZEPIR, A.P.; OKIE, W.R. Occurrence of peach tree short life on a field site with no history of peach production. HortScience, Alexandria, v.31, n.1, p.163, 1996.
OKIE, W.R.; REIGHARD, G.L.; BECKMAN, T.G.; NYCZEPIR, A.P.; REILLY, C.C.; ZEHR, E.I.; NEWALL JR., W.C.; CAIN, D.W. Field-screening Prunus for longevity in the Southeastern United States. HortScience, Alexandria, v.29, n.6, p.673677, 1994.

REILLY, C.C.; NYCZEPIR, A.P.; SHARPE, R.R.; OKIE, W.R.; PUSEY, P.L. Short life of Peach Trees as related to tree physiology, environment, pathogens, and cultural practices. Plant Disease, Saint Paul, v.70, n.6, p.538-541, 1986.

RITCHIE, D.F.; CLAYTON, C.N. Peach Tree Short Life: a complex of interacting factors. Plant Disease, Saint Paul, v.65, n.6, p.462-469, 1981.

ROSTIROLLA, P.; STRIEDER, G.; MIOLA, E.C.C.; REISSER JÚNIOR, C.; SUZIKI, L.E.A.S. Variabilidade da fertilidade de um Argissolo cultivado com pessegueiro. In: CONGRESSO DE INICIAÇÃO CIENTÍFICA, 19; ENCONTRO DE PÓS-GRADUAÇÃO, 12.; MOSTRA CIENTÍFICA, 2., 2010, Pelotas. Anais... Pelotas: UFPEL, 2010. Disponível em: < http://www2.ufpel.edu.br/cic/2010/ cd/ca.htm>. Acesso em: 10 jan. 2014.

SHARPE, R.R.; REILLY, C.C. Elemental and chemical concentration in peach tree short life and healthy trees. Communications in Soil Science and Plant Analysis, New York, v.17, n.7, p.761774, 1986.

SHARPE, R.R.; REILLY, C.C.; NYCZEPIR, A.P.; OKIE, W.R. Comparison of elemental concentrations between peach tree short life and healthy trees before and after tree death. Communications in Soil Science and Plant Analysis, New York, v.20, n.17-18, p.1.753-1.767, 1989.

STRECK, E.V.; KAMPF, N.; DALMOLIN, R.S.D. Solos do Rio Grande do Sul. 2. ed. Porto Alegre: UFRGS, EMATER-RS/ASCAR, 2008. 222p.

WEHUNT, E.J.; HORTON, B.D.; PRINCE, V.E. Effects of nematicides, lime, and herbicide on peach tree short life in Georgia. Journal of Nematology, College Park, v.12, n.3, p.183-189, 1980.

WERNER, D.; PARKER, M.L.; WHEELER, E. Potential relationship between peach tree short life symptomatology and aberrant wood anatomy. HortScience, Alexandria, v.30, n.4, p.786-787, 1995. 